\title{
Sinergia entre aditivo vegetal e níveis crescentes de promotores de crescimento sobre o desempenho produtivo e morfometria intestinal de frangos de corte
}

\author{
Synergy between vegetal additive with increase levels of growth promoter on the \\ performance and intestinal morphometry of broilers chickens
}

\author{
Fabiano Gomes Gonçalves ${ }^{\mathrm{I}}$ Surama Freitas Zanini ${ }^{\mathrm{II}}$ Dyeime Ribeiro de Sousa ${ }^{\mathrm{I}}$ \\ Maria Aparecida da Silva ${ }^{\text {III }}$ Luiz Geraldo Colnago ${ }^{\text {IV }}$
}

RESUMO

Objetivou-se avaliar o efeito da adição de níveis crescentes de antibióticos associados ao farelo integral de pimenta rosa (FIPR) sobre o desempenho produtivo e morfometria intestinal de frangos corte. Utilizaram-se 528 pintos Cobb, machos, distribuidos em um delineamento inteiramente casualizado, com seis tratamentos e quatro repetições de 22 animais cada, constituido pelos grupos T1 - Controle Negativo (CN) - Dieta basal sem FIPR e sem antibióticos; T2 - Controle Positivo (CP) - Dieta Basal com 1,2\% FIPR; T3 - CP + 11ppm bacitracina zinco e 17ppm salinomicina; $T 4-C P+22 p p m$ bacitracina zinco e $34 p p m$ salinomicina; $T 5-$ $C P+33 p p m$ bacitracina zinco e 51ppm salinomicina; T6 - CP +45 ppm bacitracina zinco e 67 ppm salinomicina. No período de 1-43 dias de idade, observou-se que a adição de FIPR com ou sem antibiótico reduziu $(P \leq 0,05)$ o consumo e melhorou a conversão alimentar, comparado com CN. Verificou-se que os frangos alimentados com FIPR associado aos antibióticos, em valores acima de $22 \mathrm{mg} \mathrm{kg}^{-1}$ de bacitracina de zinco e $34 \mathrm{mg} \mathrm{kg}^{-1}$ de salinomicina, tiveram maiores alturas de vilosidades intestinais que o $C N(P \leq 0,05)$. O FIPR pode ser utilizado em substituição aos antibióticos sem queda de desempenho animal e com a manutenção da viabilidade e do fator de produção.

Palavras - chave: fitoquímico, índices produtivos, mucosa jejunal, pimenta rosa, promotor de crescimento, Schinus terebinthifolius Raddi.

\section{ABSTRACT}

The aim of this research was to evaluate the effects of the increase levels of antibiotics associated with the pink pepper meal (PPM) on animal performance and intestinal morphometry of broilers jejunum. A total of 528 day-old male chicks, Cobb 500, distributed in a randomized design of six treatments and four replicates of 22 birds each: T1 - Negative Control (NC) - basal diet without PPM or antibiotics, T2 - Positive Control $(P C)$ - basal diet with 1,2\% PP; T3 - PC + 11ppm zinc bacitracin and $17 p p m$ salinomycin, T4 $-P C+22 p p m$ zinc bacitracin and 34ppm salinomycin, T5 - PC +33ppm zinc bacitracin and 51ppm salinomycin, T6 - PC + 45ppm zinc bacitracin and 67ppm salinomycin. In period of 1-43 days-old, it was observed that the use of PPM with or without antibiotcs reduced feed intake and improved feed:gain ratio compared with $N C(P \leq 0,05)$. It was observed that the broilers fed diet with antibiotics values of up to $22 \mathrm{mg} \mathrm{kg}^{-1}$ of zinc bacitracin and $34 \mathrm{mg} \mathrm{kg}^{-1}$ of salinomycin associated with the PPM had the higher villus height compared with NC. The PPM can be used to replace antibiotic growth promoters without decrease on animal performance, viability and production factor.

Key words: growth promoter antibiotics, jejunal mucosa, phytochemistry, produtivity, Schinus terebinthifolius Raddi.

\section{INTRODUÇÃO}

A cadeia produtiva avícola, durante décadas, utilizou os antibióticos como promotores de crescimento, visando melhorar o desempenho animal e diminuir a mortalidade (FUKAYAMA et al., 2005). No entanto, com a proibição desses aditivos na produção animal (BRUGALLI, 2003), houve estímulo para a busca de alternativas aos antibióticos promotores de crescimento por agentes não menos efetivos, mas reconhecidos como seguros (MENTEN, 2001), como os extratos vegetais, óleos essenciais, prebióticos e probióticos (SILVA et al., 2011).

IPrograma de Pós-graduação em Ciências Veterinárias, Universidade Federal do Espírito Santo (UFES), Alegre, ES, Brasil.

IIDepartamento de Medicina Veterinária, UFES, 29500-000, Alegre, ES, Brasil. E-mail: smzanini@gmail.com. Autor para correspondência.

IIIPrograma de Pós-graduação em Ciência Animal, Universidade Estadual do Norte Fluminense Darcy Ribeiro (UENF), Campos dos Goytacazes, RJ, Brasil.

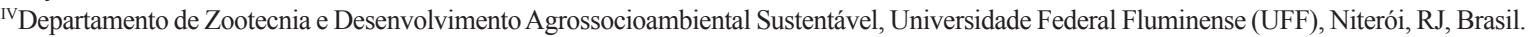
Recebido 14.10.12 Aprovado 20.02.13 Devolvido pelo autor 20.11.13 CR-2012-0983.R2 
Os fitoquímicos tornaram-se uma opção aos antibióticos, porque melhoram a digestibilidade dos alimentos, pois estimulam a produção de enzimas digestivas e de secreções entéricas, alterações na microbiota intestinal e propiciam modificações morfohistológicas do trato gastrointestinal (ZANINI et al., 2006; JAMROZ et al., 2006; OETTING et al., 2006; SILVA et al., 2010).

As alterações das características morfofuncionais da mucosa gastrintestinal podem interferir no turnover celular e consequentemente no processo absortivo de nutrientes (MACARI et al., 2008). Estudos confirmam a eficácia dos extratos vegetais na dieta de frangos de corte, na melhora da conversão alimentar e no ganho de peso (BONATO et al., 2008; GONÇALVES et al., 2012). Entretanto, a adição de extratos vegetais nas dietas também é capaz de apresentar efeitos negativos nas características de desempenho produtivo (CROSS et al., 2003).

$$
\text { A aroeira-vermelha (Schinus }
$$

terebenthifolius Raddi) e seu fruto, a pimenta rosa, é uma espécie nativa pertencente à família Anacardiaceae, que contêm flavonoides, esteroides, triterpenos, antraquinonas, saponinas e fenóis, como taninos (LIMA et al., 2006). Geralmente, a pimenta rosa é utilizada como condimento, sendo amplamente exportada para Europa. Entretanto, quando não se encontra dentro dos padrões de qualidade para exportação, pode ser utilizada na alimentação animal como um subproduto da agroindústria. Essa espécie vegetal contém compostos fitoquímicos com ação anti-inflamatória (GAZZANEO et al., 2005), antimicrobiana (MARTINEZ et al., 2000) e não promove queda no desempenho de frangos de corte (ZANINI et al., 2009).

Visando à redução do uso de promotores de crescimento na cadeia animal ou mesmo sua substituição por fitoquímicos, objetivou-se avaliar a adição de níveis crescentes de antibióticos associado ao farelo integral de pimenta rosa (FIPR) sobre a performance, o desempenho produtivo e nas características morfométricas do intestino de frangos corte.

\section{MATERIAL E MÉTODOS}

Foram utilizados 528 pintos de corte, machos, da linhagem Cobb 500, alojados em 24 boxes de $2 \mathrm{~m}^{2}$, durante o período de 1 a 43 dias de idade, distribuído em um delineamento inteiramente casualizado com seis tratamentos, quatro repetições e 22 aves por unidade experimental, sendo os grupos T1: Controle Negativo (CN) - Dieta Basal sem farelo integral de pimenta rosa (FIPR) e sem antibióticos;
T2: Controle Positivo (CP) - Dieta Basal com 1,2\% $\left(12 \mathrm{~g} \mathrm{~kg}^{-1}\right)$ de FIPR; T3: CP $+11 \mathrm{mg} \mathrm{kg}^{-1}$ de bacitracina e $17 \mathrm{mg} \mathrm{kg}^{-1}$ de salinomicina; $\mathrm{T} 4$ : $\mathrm{CP}+22 \mathrm{mg} \mathrm{kg}^{-1} \mathrm{de}$ bacitracina e $34 \mathrm{mg} \mathrm{kg}^{-1}$ de salinomicina; T5: CP + $33 \mathrm{mg} \mathrm{kg}^{-1}$ de bacitracina e $51 \mathrm{mg} \mathrm{kg}^{-1}$ de salinomicina; T6: CP $+45 \mathrm{mg} \mathrm{kg}^{-1}$ de bacitracina e $67 \mathrm{mg} \mathrm{kg}^{-1}$ de salinomicina.

No período de 1 a 21 dias de idade, os animais foram alimentados com ração inicial contendo $22 \%$ de PB e $3 \mathrm{Mcal} \mathrm{EM} \mathrm{kg}^{-1}$. Do $22^{\circ}$ ao $43^{\circ}$ dia de idade, as aves foram alimentadas com a ração crescimento/terminação com $19 \%$ PB e 3.1 Mcal EM $\mathrm{kg}^{-1}$ a base de milho e farelo de soja (Tabela 1).

Comercialmente, a dosagem recomendada de bacitracina de zinco $15 \%$ e salinomicina $12 \%$ são, respectivamente, de 44 a $66 \mathrm{mg} \mathrm{kg}^{-1}$ e 4 a $55 \mathrm{mg} \mathrm{kg}^{-1}$, para uso como promotor de produção em frangos de corte (MAPA, 2008). As adições do farelo integral de pimenta rosa e dos antibióticos foram feitos em substituição ao milho.

A composição química-bromatológica do farelo de pimenta rosa foi avaliada e os resultados publicados (GONCALVES et al., 2012), apresentando $87,1 \%$ de matéria seca, $7,1 \%$ de proteína bruta, $9,7 \%$ de extrato etéreo, $3,5 \%$ cinza, $21,3 \%$ de fibra, bruta, $45,0 \%$ de fibra detergente neutro e $22,9 \%$ de fibra detergente ácido. Os valores de fenóis totais, de taninos totais e de taninos condensados do FIPR foram de 2,86 em equivalente grama de ácido tânico por $100 \mathrm{~g}$ de matéria seca (MS), de 2,49 em equivalente grama de ácido tânico por $100 \mathrm{~g}$ de MS e de 0,18 em equivalente grama de leucocianidina por $100 \mathrm{~g}$ de $\mathrm{MS}$, respectivamente. O conteúdo dos compostos fenólicos foi determinado com base nos trabalhos de PORTER et al. (1986) e MAKKAR et al. (1988).

O manejo utilizado foi o tradicionalmente empregado nas granjas comerciais, com água e ração, na forma farelada, fornecidas à vontade durante todo o período experimental. Na tentativa de proporcionar desafio sanitário, utilizaram-se 50\% de cama reutilizada de casca de café. Os parâmetros de desempenho avaliados foram, ganho de peso, consumo de ração, conversão alimentar, viabilidade $\mathrm{e}$ fator de produção $[\mathrm{FP}=($ peso*viabilidade $) /($ conversão alimentar*idade)].

No $43^{\circ}$ dia de idade, após jejum de 12 horas, seis aves por tratamento foram escolhidas de acordo com o peso médio de cada boxe e abatidas por meio de deslocamento cervical para coleta de fragmentos de jejuno com quatro centímetros de comprimento, a partir da porção distal da alça duodenal até o divertículo de Meckel (SILVA et al., 
Tabela 1 - Índices de produtividade de frangos de corte alimentados com farelo integral de pimenta rosa com ou sem antibióticos.

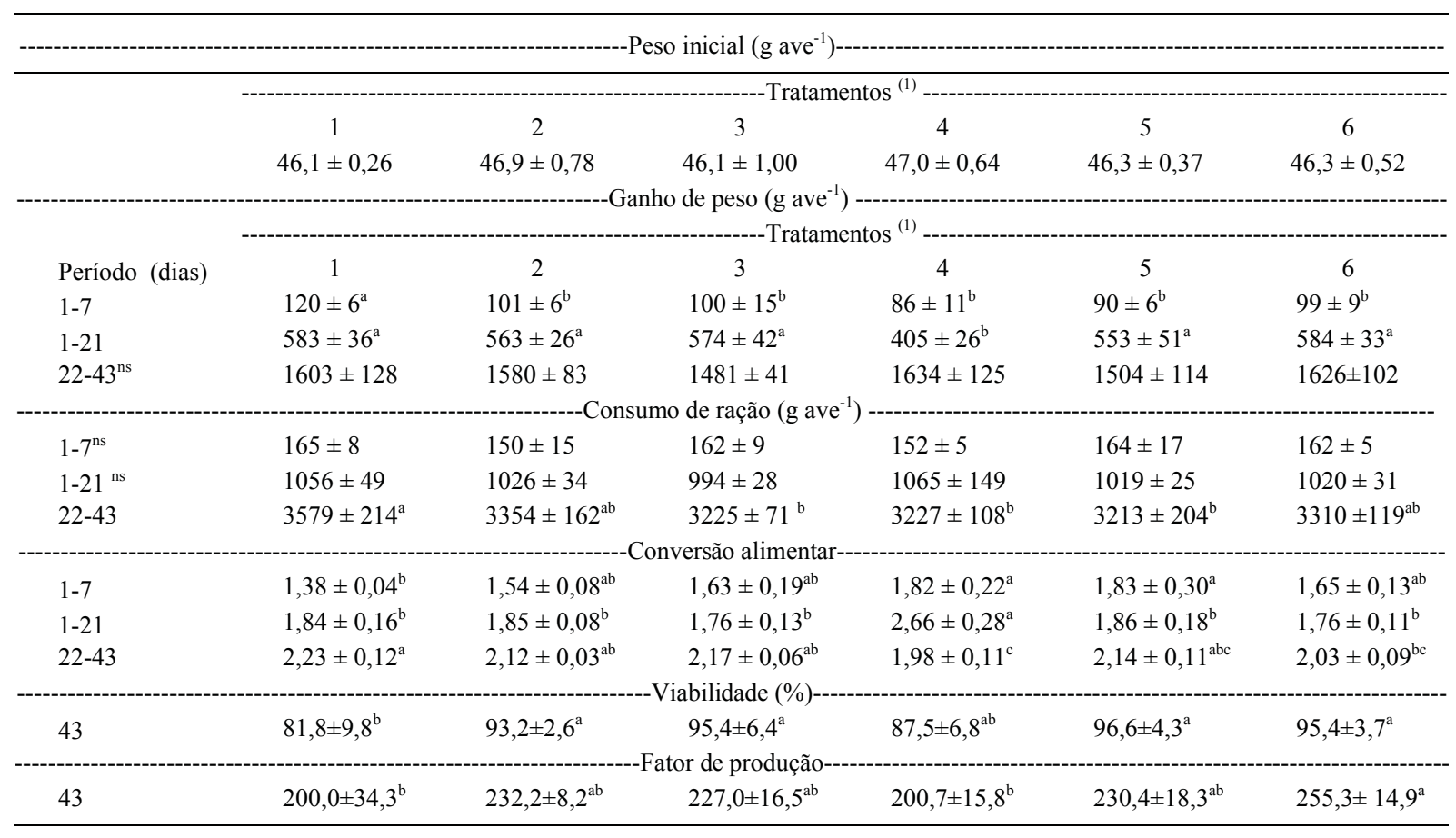

${ }^{\mathrm{ab}}$ Médias seguidas de letras diferentes na mesma linha diferem significativamente pelo teste $\mathrm{SNK}(\mathrm{P} \leq 0,05)$; ${ }^{\text {ns }}$ Efeito não significativo $(\mathrm{P}>0,05) ;{ }^{(1)} 1$ - Controle Negativo - Ração basal sem antibiótico e sem FIPR; 2 - Controle Positivo - Ração basal com $1,2 \%\left(12 \mathrm{~g} k \mathrm{~kg}^{-1}\right)$ de FIPR; $3-\mathrm{CP}+11 \mathrm{mg} \mathrm{kg}^{-1}$ de bacitracina de Zinco e $17 \mathrm{mg} \mathrm{kg}^{-1}$ de salinomicina; $4-\mathrm{CP}+22 \mathrm{mg} \mathrm{kg}^{-1}{\mathrm{de} \mathrm{bacitracina} \mathrm{e} 34 \mathrm{mg}^{-1} \mathrm{~kg}}^{-1}$

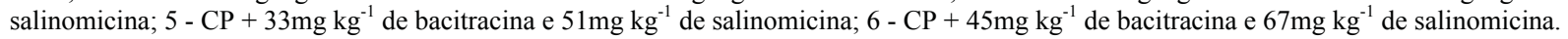

2010). Esse material foi imediatamente lavado em solução fisiológica e fixado em solução de Bouin. Os fragmentos foram submetidos ao processo de inclusão em parafina, de acordo com a técnica histopatológica de rotina. Secções com espessura de sete $\mu \mathrm{m}$ foram coradas com hematoxilina-eosina. Foram feitas mensurações no jejuno, de acordo com MAIORKA et al. (2000), da altura da vilosidade intestinal, desde o epitélio luminal até a camada muscular da mucosa e da profundidade da cripta, medida do epitélio luminal da cripta até a muscular da mucosa e a relação vilo:cripta. Efetuaram-se cinco leituras por parâmetro em cada ave, totalizando 30 leituras por tratamento. A morfometria do jejuno foi realizada utilizandose microscópio óptico com aumento de 100 vezes (objetiva 10x). A captura de imagem foi feita com Câmera Olympus Polaroid e sua análise foi feita a partir do software Sigma Scan Pro 5.0.

Os resultados foram submetidos à análise de variância e, quando significativos, as médias foram comparadas pelo teste de Student Newman Keuls $(\mathrm{P}<0,05)$, com a utilização do programa SAEG (Sistema para Análises Estatísticas e Genéticas), versão 5,0 (UFV, 1997).

\section{RESULTADOS E DISCUSSÃO}

Neste experimento, observou-se que no período pré-inicial (1-7 dias de idade) a ausência de antibiótico e de FIPR resultou em maior ganho de peso e maximização da conversão alimentar sem interferir no consumo de ração das aves (Tabela 1), quando comparado com os tratamentos que tiveram tais aditivos em sua composição $(\mathrm{P} \leq 0,05)$. De acordo com FURLAN et al. (2004), o muco presente no trato-gastrointestinal (TGI) funciona como falsos receptores para os microorganismos e esta camada de muco pode ser reduzida com o uso de antibióticos. Portanto, acredita-se que o maior ganho de peso e melhora na conversão alimentar dos frangos do grupo $\mathrm{CN}$, na primeira semana de idade, deva-se ao efeito protetor do muco, aliado a um leve desafio sanitário. A partir desse resultado, sugere-se o uso de antibióticos somente a partir da segunda semana de idade, considerando a imunidade passiva e sendo mantidas as condições de manejo sanitário durante este período.

O crescimento inicial de frangos de corte pode ser influenciado por vários fatores, dentre eles 
o nível das enzimas pancreáticas e intestinais, área de superfície do trato gastrintestinal, transportadores de nutrientes e, sobretudo, pela digestibilidade dos nutrientes (DIBNER, 1996). O pior ganho de peso e conversão alimentar nos animais alimentados com farelo integral de pimenta rosa, no período de 1-7 dias de idade $(\mathrm{P} \leq 0,05)$, pode ter sido devido ao conteúdo de taninos na ração, embora este efeito negativo não tenha sido observado posteriormente $(\mathrm{P}>0,05)$. Segundo NUNES et al. (2001), os taninos podem causar problemas na digestão dos alimentos, por formar complexos com proteínas, se acima de $1 \%$, assim como podem diminuir a digestibilidade de metionina, aminoácido limitante ao desenvolvimento de aves (TEIXEIRA, 2001). Além disso, sabe-se que alterações fisiológicas, metabólicas e anatômicas são significativas na primeira semana de idade das aves, que sugerem práticas nutricionais diferenciadas, decorrentes das dificuldades em digerir e absorver certos nutrientes, pois, o aparelho digestivo encontrase imaturo (MAIORKA et al., 2002).

À medida que os animais se desenvolveram, a adição do FIPR na dieta deixou de ser um fator limitante no crescimento animal, pois, com o aumento da idade da ave, ocorre máxima atividade das enzimas digestivas (NITSAN et al., 1991). Vale ressaltar também que os valores de taninos condensados no FIPR não ultrapassaram $1 \%$, não interferindo, negativamente, no desempenho das aves (Tabela 1). ZANINI et al. (2009) verificaram que a adição de até 1,2\% do FIPR não afetou o desempenho final das aves. Posteriormente, GONÇALVES et al. (2012) verificaram que a adição do farelo de pimenta rosa com ou sem promotor de produção não teve efeito $(\mathrm{P}>0,05)$ sobre o peso das aves e sobre o peso relativo do fígado.

No período de 1-43 dias de idade, observouse que a adição do FIPR com ou sem antibiótico reduziu o consumo de ração $(\mathrm{P} \leq 0,05)$, sem influenciar $(\mathrm{P}>0,05)$ no ganho de peso corporal, comparado com o $\mathrm{CN}$, que apresentou a pior conversão alimentar neste período $(\mathrm{P} \leq 0,05)$. Esses resultados estão de acordo com CORNELI (2004), que verificou maior consumo para as aves do tratamento sem adição de promotores de crescimento, ao comparar com as aves tratadas com antibióticos $(\mathrm{P} \leq 0,05)$. Os resultados do presente estudo condizem com MAIORKA et al. (2001), que verificaram piora na conversão alimentar quando nenhum aditivo foi adicionado na dieta das aves.

Sugere-se que o efeito da adição de FIPR com ou sem promotor de produção tenha sido verificado somente na fase de crescimento, devido à maior carga microbiana no ambiente, em virtude do acúmulo de excretas, em cama reutilizada, o que proporcionou maior desafio sanitário. Desse modo, foi possível identificar diferença $(\mathrm{P} \leq 0,05)$ na conversão alimentar, na viabilidade e no fator de produção entre o controle negativo e os demais tratamentos, pois, os animais alimentados com dieta sem antibióticos tiveram maior consumo de ração e maior mortalidade, quando comparado aos demais tratamentos $(\mathrm{P} \leq 0,05$, Tabela 1$)$.

Considerando o índice de viabilidade, verificou-se diferença $(\mathrm{P} \leq 0,05)$ entre os tratamentos, sendo que a adição de FIPR com ou sem promotor de produção resultou em melhoria no percentual de viabilidade, quando comparado com o controle negativo. Para o fator de produção, verificou-se que a adição de FIPR com $45 \mathrm{mg} \mathrm{kg}^{-1}$ de bacitracina de zinco $+67 \mathrm{mg} \mathrm{kg}^{-1}$ de salinomicina alcançou a melhor conversão alimentar, diferindo $(\mathrm{P} \leq 0,05)$ do controle negativo, que apresentou o pior fator de produção.

Com relação à morfometria intestinal, não foi observado efeito $(\mathrm{P}>0,05)$ dos tratamentos sobre o peso relativo do intestino, a profundidade de cripta e relação vilo:cripta (Tabela 2). Entretanto, verificou-se diferença $(\mathrm{P} \leq 0,05)$ na altura de vilosidades entre os tratamentos, sendo que os frangos alimentados com FIPR associado aos antibióticos, com valores acima de $22 \mathrm{mg} \mathrm{kg}^{-1}$ de bacitracina de zinco e $34 \mathrm{mg} \mathrm{kg}^{-1}$ de salinomicina, tiveram maiores alturas de vilosidades, comparadas ao controle negativo. Provavelmente, a maior altura de vilosidades foi responsável pela melhoria nos processos de digestão e absorção de nutrientes, tornando-os mais eficientes, visualizado pela otimização da conversão alimentar, como observado na literatura (SILVA et al., 2010).

O efeito da adição do FIPR integral de pimenta rosa sobre a superfície absortiva intestinal pode ser atribuído à presença de substâncias fenólicas na Schinus terebinthifolius Raddi que apresentam ação anti-inflamatória (GAZZANEO et al., 2005) e antimicrobiana (LIMA et al., 2006). De acordo com MACARI et al. (2008), a capacidade absortiva do intestino é proporcional ao número de vilosidades, sendo que a redução do tamanho das vilosidades, resulta em diminuição da eficiência absortiva intestinal que, na prática, se traduz em piora na conversão alimentar e no ganho de peso dos animais (FURLAN et al., 2004).

\section{CONCLUSÃO}

Nas condições em que o experimento foi desenvolvido, concluiu-se que: na fase pré-inicial (1-7 dias de idade), não se recomenda o uso do 
Tabela 2 - Peso relativo da seção intestinal (PRI), altura de vilo $(\mu \mathrm{m})$, profundidade de cripta ( $\mu \mathrm{m})$ e relação vilo:cripta (v:c) do jejuno de frangos de corte aos 43 dias de idade, alimentados com farelo integral de pimenta rosa com ou sem antibióticos.

\begin{tabular}{|c|c|c|c|c|}
\hline Tratamentos & PRI $(\%)^{\text {ns }}$ & Altura vilo & Profundidade/cripta ${ }^{\text {ns }}$ & $\mathrm{V}: \mathrm{C}^{\mathbf{n s}}$ \\
\hline 1. Controle Negativo ${ }^{(1)}$ & $5,57 \pm 0,44$ & $1.060 \pm 174^{\mathrm{b}}$ & $205 \pm 35$ & $5,32 \pm 0,88$ \\
\hline 2. Controle Positivo ${ }^{(2)}$ & $5,35 \pm 0,43$ & $1.269 \pm 159^{\mathrm{ab}}$ & $196 \pm 42$ & $6,70 \pm 1,49$ \\
\hline 3. $\mathrm{CP}+11 \mathrm{mg} \mathrm{kg}^{-1}$ bac $\mathrm{Zn}$ e $17 \mathrm{mg} \mathrm{kg}^{-1}$ sal & $5,41 \pm 1,05$ & $1.339 \pm 264^{\mathrm{ab}}$ & $230 \pm 25$ & $5,83 \pm 1,15$ \\
\hline 4. $\mathrm{CP}+22 \mathrm{mg} \mathrm{kg}^{-1}$ bac $\mathrm{Zn}$ e $34 \mathrm{mg} \mathrm{kg}^{-1}$ sal & $5,98 \pm 0,45$ & $1.418 \pm 180^{\mathrm{a}}$ & $186 \pm 30$ & $7,75 \pm 1,7$ \\
\hline 5. $\mathrm{CP}+33 \mathrm{mg} \mathrm{kg}^{-1}$ bac $\mathrm{Zn}$ e $51 \mathrm{mg} \mathrm{kg}^{-1} \mathrm{sal}$ & $5,51 \pm 0,87$ & $1.433 \pm 181^{\mathrm{a}}$ & $234 \pm 32$ & $6,23 \pm 1,31$ \\
\hline 6. $\mathrm{CP}+45 \mathrm{mg} \mathrm{kg}^{-1}$ bac $\mathrm{Zn}$ e $67 \mathrm{mg} \mathrm{kg}^{-1} \mathrm{sal}$ & $5,50 \pm 0,73$ & $1.408 \pm 124^{\mathrm{a}}$ & $191 \pm 24$ & $7,47 \pm 1,33$ \\
\hline $\mathrm{CV}(\%)$ & 12,7 & 14,05 & 15,57 & 21,31 \\
\hline
\end{tabular}

${ }^{a b}$ Médias seguidas de letras diferentes na mesma coluna diferem significativamente pelo teste $\mathrm{SNK}(\mathrm{P} \leq 0,05)$; ${ }^{\text {ns }}$ Efeito não significativo $(\mathrm{P}>0,05) ;{ }^{(1)}$ Controle negativo - Ração basal sem antibiótico e sem FIPR; ${ }^{(2)}$ Controle positivo - Ração basal com $1,2 \%\left(12 \mathrm{~g}\right.$ kg $\left.{ }^{-1}\right)$ de FIPR. Idem 1

farelo integral de pimenta rosa ou de antibiótico, pois se verifica queda de desempenho animal; no período total de criação, a adição de farelo integral de pimenta rosa com ou sem antibióticos reduz o consumo de ração sem influenciar o ganho de peso e melhora a conversão alimentar, a viabilidade e o fator de produção; a adição do farelo integral de pimenta rosa aumenta o tamanho das vilosidades intestinais comparado com o controle negativo; o farelo integral de pimenta rosa pode ser utilizado em substituição aos antibióticos promotores de produção sem queda no desempenho animal, com a manutenção da viabilidade e do fator de produção.

\section{AGRADECIMENTOS}

Ao Conselho Nacional de Desenvolvimento Científico e Tecnológico (CNPq), pelo apoio financeiro concedido para execução desta pesquisa.

\section{COMITÊ DE ÉTICA E BIOSSEGURANÇA}

O protocolo de experimentação animal está de acordo com CONEA e foi aprovado pelo comitê de ética no uso de animais da Universidade Federal do Espírito Santo, pelo protocolo no 01/08.

\section{REFERÊNCIAS}

BONATO, M.A. et al. Efeito de acidificantes e extratos vegetais sobre o desempenho e qualidade de ovos de poedeiras comerciais. Ars Veterinaria, v.24, n.3, p.186-192, 2008.

BRUGALLI, I. Alimentação alternativa: a utilização de fitoterápicos ou nutracêuticos como moduladores da imunidade e desempenho animal. In: SIMPÓSIO SOBRE MANEJO E NUTRIĈ̃̃O DE AVES E SUÍNOS, 2003, Campinas, SP. Anais... Campinas: Colégio Brasileiro de Nutrição Animal, 2003. p.167-182.

CORNELI, J. Avaliação de promotores de crescimento alternativos em substituição aos convencionais sobre o desempenho, características de carcaça e morfometria intestinal em frangos de corte. 2004. 46f. Dissertação (Mestrado em Zootecnia) - Universidade Federal de Santa Maria, RS.
CROSS, D.E. et al. The performance of chickens fed diets with and without thyme oil and enzymes. British Poultry Science, v.44, supl. 01, p.18-19, 2003. Disponível em: <http://www.tandfonline. com/doi/abs/10.1080/713655293 > . Acesso em: 02 out. 2012.

DIBNER, J. Nutritional requirements of young poultry. In: MEETING OF ARKANSAS NUTRITION CONFERENCE, 1996, Fayetteville. Proceedings... Fayetteville: Arkansas Poultry Federation, 1996. p.15-27.

FUKAYAMA, E.H. et al. Extrato de orégano como aditivo em rações para frangos de corte. Revista Brasileira de Zootecnia, v.34, n.6, p.2316-2326, 2005. Disponível em: <http://dx.doi.org/10.1590/ S1516-35982005000700018>. Acesso em: 02 out. 2012.

FURLAN, R.L. et al. Como avaliar os efeitos do uso de probióticos, probióticos e flora de exclusão competitiva. In: SIMPÓSIO TÉCNICO DE INCUBAÇÃO, MATRIZES DE CORTE E NUTRIÇÃO, 5., 2004, Balneário de Camboriu, SC. Anais... Balneário Camboriú: ACAV, 2004. p. 06-28.

GAZZANEO, L.R.S. et al. Knowledge and use of medicinal plants by local specialists in a region of Atlantic Forest in the state of Pernambuco (Northeastern Brazil). Journal of Ethnobiology and Ethnomedicine, v.1, n.9, p.1-8, 2005. Disponível em: <http:// www.ncbi.nlm.nih.gov/pmc/articles/PMC1291389/pdf/17464269-1-9.pdf>. Acesso em: 02 out. 2012.

GONCALVES, F.G. et al. Efeito da pimenta rosa associada a diversas dosagens de antibióticos em frangos de corte. Ciencia Rural, v.42, n.8, p.1503-1509, 2012. Disponível em: < http://www.scielo.br/pdf/ cr/v42n8/a22412cr4269.pdf>. Acesso em: 02 out. 2012.

JAMROZ, D. et al. Influence of diet type on the inclusion of plant origin active substances on morphological and histochemical characteristics of the stomach and jejunum walls in chicken. Journal of Animal Physiology and Animal Nutrition, v.90, n.5-6, p.255-268. Disponível em: <http://onlinelibrary.wiley.com/doi/10.1111/j.14390396.2005.00603.x/pdf>. Acesso em: Acesso em: 02 out. 2012.

LIMA M.R.F. et al. The antibiotic activity of some Brazilian medicinal plants. Revista Brasileira Farmacognosia, v.16, n.3, p.300-306, 2006. Disponível em: < http://dx.doi.org/doi:10.1590/ S0102-695X2006000300004>. Acesso em: 03 out. 2012.

MACARI, M. et al. Fisiologia aplicada a frangos de corte. In: Imunologia aplicada. 2ed. Jaboticabal: Funep, FCAV/ Unesp, 2008. Cap.18, p. 231-245. 
MAIORKA, A. et al. Desenvolvimento e reparo da mucosa intestinal. In: MACARI, M. et al. Fisiologia aviária aplicada a frangos de corte. 2.ed. Jaboticabal:FUNEP/UNESP, 2002. Cap.8, p.113-124.

MAIORKA, A. Adaptações digestivas pós-eclosão. In CONFERÊNCIA APINCO DE CIÊNCIA E TECNOLOGIA AVÍCOLAS, 2001, Campinas, SP. Anais... Campinas: FACTA, 2001. p.141-152.

MAIORKA, A. et al. Influência da suplementação de glutamina sobre o desempenho e o desenvolvimento de vilos e criptas do intestino delgado de frangos. Arquivo Brasileiro de Medicina Veterinária e Zootecnia, v.52, n.5, p.487-490, 2000. Disponível em:<http://dx.doi.org/10.1590/S0102-09352000000500014>. Acesso em: 3 maio 2012

MAIORKA, A. et al. Utilização de prebióticos, probióticos ou simbióticos em dietas para frangos. Revista Brasileira de Ciência Avícola, v.3, n.1, 2001. Disponível em: <http://dx.doi.org/10.1590/ S1516-635X2001000100008>. Acesso em: 03 out. 2012.

MAKKAR, H.P.S. et al. Determination of both tannin and protein in a tannin-protein complex. Journal of Agricultural and Food Chemistry, v.36, p.523-525, 1988.

MARTINEZ, M.J. et al. Actividad antimicrobiana del Schinus terebenthifolius Raddi (copal). Revista Cubana Plantas Medicinais, v.5, n.1, p.37-9, 2000. Disponível em: <http://scielo. sld.cu/scielo.php?script=sci_arttext\&pid=S102847962000000100 006\&lng=es\&nrm=iso > . Acesso em: 13 out. 2012.

MENTEN, J.F.M. Aditivos alternativos na produção de aves: probióticos e prebióticos. In: REUNIÃO ANUAL DA SOCIEDADE BRASILEIRA DE ZOOTECNIA, 2001, Piracicaba, SP. Anais... Piracicaba: FEALQ, 2001. p.141-157.

MINISTERIO DA AGRICULTURA E PECUARIA (MAPA), 2008. Disponível em $<$ http://wwwagricultura.gov.br/> . Acesso em: 22 nov. 2010.

NITSAN Z, et al. Growth and development of the digestive organs and some enzymes in broiler chicks after hatching. British Poultry Science, v.32, n.3, p.515-523, 1991. Disponível em: $<$ http://www. tandfonline.com/doi/pdf/10.1080/00071669108417376>. Acesso em: 04 out. 2012 .
NUNES, R.V. et al. Fatores antinutricionais dos ingredientes destinados à alimentação animal. In: SIMPÓSIO SOBRE INGREDIENTES NA ALIMENTAÇÃO ANIMAL, 2001, Campinas, SP. Anais... Campinas: CBNA, 2001. p. 235-272.

OETTING, L.L. et al. Efeitos de extratos vegetais e antimicrobianos sobre a digestibilidade aparente, o desempenho, a morfometria dos órgãos e a histologia intestinal de leitões recémdesmamados. Revista Brasileira de Zootecnia, v.35, n.4, p.13891397, 2006. Disponível em: <http://dx.doi.org/10.1590/S151635982006000500019>. Acesso em: 03 out. 2012.

PORTER, L.J. et al. The conversion of procyanidins and prodelphinidins to cyanidin and delphinidin. Phytochemistry, v. 25, p. $223-230,1986$

SILVA, M.A. et al. Óleo de aroeira-vermelha sobre o desempenho e a morfometria intestinal de frangos de corte. Ciência Rural, v.40, n.10, p.2151-2156, 2010. Disponível em: <http://www.scielo. br/pdf/cr/v40n10/a732cr3585.pdf>. Acesso em: 05 nov. 2012.

SILVA, M.A. da et al. Óleo essencial de aroeira-vermelha como aditivo na ração de frangos de corte. Ciência Rural, v.41, n.4, p.676-681, 2011. Disponível em: <http://www.scielo.br/pdf/cr/ v41n4/a923cr3695.pdf>. Acesso em: 19 jun. 2011. Doi: 10.1590/ S0103-84782011005000034.

TEIXEIRA, A.S. Alimentos e alimentação dos animais. 5.ed. Lavras: UFLA, FAEPE, 2001 p.241.

UFV (UNIVERSIDADE FEDERAL DE VICOSA). Manual de utilização do Programa SAEG (Sistemas Para Análises Estatísticas e Genéticas). Viçosa, MG, 1997. 59p.

ZANINI, M.S. et al. Avaliação do óleo de orégano e da suplementação de vitamina E na dieta de frangos de corte sobre a microbiota intestinal na ausência de promotor de crescimento e anticoccidiano. Brazilian Journal of Poultry Science, v.8, p.140, 2006.

ZANINI, S.F. et al. Evaluación del nível de inclusión de salvado de aroeira-roja (Schinus terebinthifolius Raddi) en la dieta de pollos de engorde. In: CONGRESSO LATINOAMERICANO DE AVICUlTURA, 11., 2009, Cuba. Anais... Cuba: La Habana, 2009. p. 552-554. 